\title{
Uremic Pericarditis
}

National Cancer Institute

\section{Source}

National Cancer Institute. Uremic Pericarditis. NCI Thesaurus. Code C114837.

Inflammation of the pericardium associated with chronic kidney failure. 